\title{
Dietary restriction reduces angiogenesis and growth in an orthotopic mouse brain tumour model
}

\section{P Mukherjee', MM El-Abbadi', JL Kasperzyk', MK Ranes' and TN Seyfried*,I}

'Biology Department, Boston College, Chestnut Hill, Massachusetts, MA 02467, USA

\begin{abstract}
Diet and lifestyle produce major effects on tumour incidence, prevalence, and natural history. Moderate dietary restriction has long been recognised as a natural therapy that improves health, promotes longevity, and reduces both the incidence and growth of many tumour types. Dietary restriction differs from fasting or starvation by reducing total food and caloric intake without causing nutritional deficiencies. No prior studies have evaluated the responsiveness of malignant brain cancer to dietary restriction. We found that a moderate dietary restriction of $30-40 \%$ significantly inhibited the intracerebral growth of the CT-2A syngeneic malignant mouse astrocytoma by almost $80 \%$. The total dietary intake for the ad libitum control group $(n=9)$ and the dietary restriction experimental group $(n=10)$ was about 20 and $13 \mathrm{Kcal}$ day ${ }^{-1}$, respectively. Overall health and vitality was better in the dietary restriction-fed mice than in the ad libitum-fed mice. Tumour microvessel density (Factor VIII immunostaining) was two-fold less in the dietary restriction mice than in the ad libitum mice, whereas the tumour apoptotic index (TUNEL assay) was three-fold greater in the dietary restriction mice than in the ad libitum mice. CT-2A tumour cellinduced vascularity was also less in the dietary restriction mice than in the ad libitum mice in the in vivo Matrigel plug assay. These findings indicate that dietary restriction inhibited CT-2A growth by reducing angiogenesis and by enhancing apoptosis. Dietary restriction may shift the tumour microenvironment from a proangiogenic to an antiangiogenic state through multiple effects on the tumour cells and the tumour-associated host cells. Our data suggest that moderate dietary restriction may be an effective antiangiogenic therapy for recurrent malignant brain cancers.

British Journal of Cancer (2002) 86, 1615-1621. DOI: 10.1038/sj/bjc/6600298 www.bjcancer.com

(c) 2002 Cancer Research UK
\end{abstract}

Keywords: glioma; glycolysis; inflammation; energy metabolism; caloric restriction; microenvironment

About 35000 people in the United States are diagnosed each year with primary or secondary brain tumours (Black, 1991). The prognosis for many of these patients is poor despite new developments in neurosurgery, chemotherapy, and radiotherapy (Shapiro, 1999). Moreover, while the incidence of many cancers is decreasing, the incidence of brain cancer is increasing in both children and the elderly (Lowry et al, 1998; Kaiser, 1999; McKinley et al, 2000). The highly infiltrative growth of malignant brain tumours and difficulties in drug penetration of the neural parenchyma have limited therapeutic options. Hence, there is a crucial need for new and better brain tumour therapeutic strategies.

Several studies suggest that differences in diet and lifestyle can have major effects on tumour incidence, prevalence, and natural history (Blowers et al, 1997; Kaplan et al, 1997; Hu et al, 1999). Dietary restriction (DR) has long been recognised as a natural therapy that improves health, promotes longevity, and significantly reduces both the incidence and growth of many tumour types (Rous, 1914; Tannenbaum, 1959; Weindruch and Walford, 1988; Birt et al, 1999; Kritchevsky, 1999b). Dietary restriction differs from severe fasting or starvation in that it reduces total caloric or energy intake without causing deficiencies of any specific nutrients (Tannenbaum, 1959; Mukherjee et al, 1999a). The mechanisms by which DR reduces tumour growth are not yet clear, but likely

*Correspondence: TN Seyfried; E-mail: thomas.seyfried@bc.edu Received 17 December 200 I; revised 4 March 2002; accepted II March 2002 involve changes in tumour cells and in tumour associated host cells.

Rous first suggested that DR might inhibit tumour growth by delaying host-mediated tumour vascularisation (Rous, 1914). Pili et al (1994) and Mukherjee et al (1999a) later provided direct support for Rous' hypothesis by showing that DR was antiangiogenic in experimental sarcomas and prostate tumours, respectively. Moreover, the antiangiogenic effect of DR was observed whether the calories were derived from fats or carbohydrates suggesting that tumour angiogenesis may be more sensitive to reductions in the amount rather than in the type of calories (Mukherjee et al, 1999a). Reduced total energy intake through DR may inhibit tumour growth by shifting tumour-host cell interactions from a proangiogenic to an antiangiogenic state.

Since neural tissues utilise glucose as the main energy substrate (Clarke and Sokoloff, 1999), brain tumours may be responsive to dietary and nutritional therapies. Moreover, the reliance of brain tumours on glycolysis for energy should make them especially vulnerable to DR, as DR shifts energy metabolism from glucose to ketone utilisation (Oudard et al, 1997; Greene et al, 2001). With the exception of an anecdotal report on the potential efficacy of a ketogenic diet toward paediatric astrocytoma (Nebeling et al, 1995), no studies have been performed to our knowledge on the effects of DR as a therapeutic intervention for brain tumours. In this study, we show for the first time that moderate DR can inhibit growth and vascularisation and enhance apoptosis in an orthotopic mouse brain tumour model. A preliminary account of these findings has appeared (Mukherjee et al, 2001). 


\section{MATERIALS AND METHODS}

\section{Mice}

Mice of the C57BL/6J strain and the BALBc/J-SCID (severe combined immuno deficiency) strain were obtained from the Jackson laboratory (Bar Harbor, ME, USA). The mice were propagated in the animal care facility of the department of Biology of Boston College, using animal husbandry conditions described previously (Flavin et al, 1991). Male mice (8-10 weeks of age ) were used for the studies and were provided with food either ad libitum (AL) or under restricted conditions (as below). Water was provided AL to all mice. The animal room was maintained at $22 \pm 1^{\circ} \mathrm{C}$ and cotton nesting pads were provided for additional warmth. All animal experiments were carried out with ethical committee approval in accordance with the National Institutes of Health Guide for the Care and Use of Laboratory Animals and were approved by the Institutional Care Committee. Also, these procedures meet the standards required by the UKCCCR guidelines (Workman et al, 1998).

\section{Brain tumour model}

The syngeneic CT-2A experimental mouse brain tumour used for these studies was generated in our laboratory after implantation of 20-methylcholanthrene into the cerebral cortex of a C57BL/6J mouse according to the procedure of Zimmerman (Zimmerman and Arnold, 1941; Seyfried et al, 1992). Histologically, the CT-2A brain tumour is broadly classified as a poorly differentiated highly malignant anaplastic astrocytoma (Seyfried et al, 1992). The tumour grows orthotopically as a soft, noncohesive, and highly vascularised mass.

\section{Intracerebral tumour implantation}

The CT-2A tumour was implanted into the cerebral cortex of C57BL/6J mice using a trocar as we previously described (Seyfried et al, 1987; Ranes et al, 2001). Briefly, mice were anaesthetised with pentobarbital (Vet Labs, Inc) intra-peritoneally and their heads were shaved and swabbed with $70 \%$ ethyl alcohol under sterile conditions. Small CT-2A tumour pieces (about $1 \mathrm{~mm}^{3}$ ) from a C57BL/6J donor mouse were implanted into the right cerebral hemisphere of anaesthetised recipient mice as we recently described (Ranes et al, 2001). All of the mice recovered from the surgical procedure and were returned to their cages when fully active. Initiation of tumours from intact tumour pieces is preferable to initiation from cultured cells since the pieces already contain an established microenvironment that facilitates tumour growth.

\section{Dietary restriction}

The mice were group housed prior to the initiation of the experiment and were then separated and randomly assigned to either a control group that was fed $\mathrm{AL}$ or to an experimental group that was fed a total DR of $30 \%$ ( $70 \%$ of the control group). Each mouse was housed singly in a plastic shoe box cage with a filter top and was given a cotton nesting pad for warmth. Dietary restriction was initiated 7 days prior to tumour implantation and was continued for either 11 or 14 days after implantation. Total DR maintains a constant ratio of nutrients to energy, i.e., the average daily food intake (grams) for the AL fed mice was determined every other day and the DR-fed mice were given $70 \%$ of that quantity on a daily basis (Mukherjee et al, 1999a). All mice received PROLAB chow (Agaway Inc.), which contains a balance of mouse nutritional ingredients and, according to the manufacturer's specification, delivers $4.4 \mathrm{Kcal} \mathrm{g}^{-1}$ gross energy. Body weights of all mice were recorded every other day.

\section{Tumour growth}

Intracerebral tumour growth was analysed directly by measuring total tumour dry weight. Tumours were dissected from normal appearing brain tissue, were frozen, and were then lyophilised to remove water. From our experience, total tumour dry weight is a more accurate measure of tumour growth than total wet weight because individual CT-2A tumours can vary in the degree of haemorrhage and oedema.

\section{Histology}

Tumour samples were fixed in $10 \%$ neutral buffered formalin (Sigma) and embedded in paraffin. Tumours were sectioned at $5 \mathrm{um}$, stained with haematoxylin and eosin, and examined by light microscopy.

\section{Factor VIII staining and microvessel quantitation}

After deparaffinisation, rehydration, and washing, the tumour sections were incubated with trypsin at $37^{\circ} \mathrm{C}$ for $30 \mathrm{~min}$ as we recently described for prostate tumours (Mukherjee et al, 1999a). Briefly, the sections were quenched with $0.3 \% \mathrm{H}_{2} \mathrm{O}_{2}$-methanol for $30 \mathrm{~min}$ and then blocked with $10 \%$ normal goat serum in PBA buffer $(100 \mathrm{ml}$ of $0.01 \mathrm{M}$ phosphate buffer with $0.9 \%$ sodium chloride, and $1.0 \mathrm{~g}$ bovine serum albumin and $0.1 \mathrm{ml}$ Tween 20 , $\mathrm{pH}$ 7.4). The sections were treated with rabbit polyclonal antibody directed against human factor VIII-related antigen (Dako Corp., Carpinteria, CA, USA; 1:100 dilution with PBA) followed by a biotinylated anti-rabbit IgG at $1: 100$ dilution (Vector Laboratories, Inc., Burlingame, CA, USA). The sections were then treated with avidin-biotin complex followed by $3-3^{\prime}$ diaminobenzidine as substrate for staining according to the manufacturer's directions (Vectastain Elite ABC kit ; Vector Laboratories, Inc.). The sections were then rinsed three times with PBS $(0.01 \mathrm{M}$ phosphate buffer with $0.9 \% \mathrm{NaCl})$. Sections were counter stained with methyl green and mounted. Corresponding tissue sections without primary antibody served as negative controls. Microvessel density was quantified by examining areas of vascular hotspots as previously described by Weidner et al (1991) with some modifications. Sections were scanned at low magnification $(40 \times$ and $100 \times)$ for the localisation of vascular hotspots. The three most vascular areas of the tumour, not containing necrosis, were determined and then counted at higher magnification $(200 \times)$. The values of the three sections were averaged and the results of three independent CT2A tumours were analyzed. Branching structures were counted as a single vessel as previously shown (Mukherjee et al, 1999a).

\section{In situ apoptotic cell detection (TUNEL)}

Apoptotic cells were detected using the ApopTag in situ detection kit TUNEL (terminal deoxynucleotidyl transferase mediated deoxyuridine triphosphate biotin nick end labelling) (Oncor, Gaithersberg, MD, USA) as we previously described (Mukherjee et al, 1999a). After deparaffinisation, rehydration and washing in PBS, the tissue sections were treated with proteinase $\mathrm{K}$ $\left(20 \mu \mathrm{g} \mathrm{ml}^{-1}\right)$ for $15 \mathrm{~min}$ at room temperature and were then washed in PBS. The sections were treated with $3 \% \mathrm{H}_{2} \mathrm{O}_{2}$ in PBS for $5 \mathrm{~min}$ to quench endogenous peroxide activities. The $3^{\prime}$ hydroxy DNA strand breaks were enzymatically labelled with digoxygeninnucleotide via TdT and incubated for $1 \mathrm{~h}$ at $37^{\circ} \mathrm{C}$. The reaction was terminated with stop buffer according to the manufacturer's protocol. Sections were then treated with antidegoxygenin peroxidase for $30 \mathrm{~min}$ at room temperature, washed, stained with 3-3' diaminobenzidine substrate, counter stained with hematoxylin, and finally were mounted. Tissue sections of post weaning normal female mouse mammary glands, provided by Oncor, were used as a positive control and staining of a corre- 
sponding tissue section without added TdT served as the negative control.

The apoptotic index was expressed as $\mathrm{AI} \%=\mathrm{A} \times 100 /(\mathrm{A}+\mathrm{C})$, where $\mathrm{A}=\mathrm{TUNEL}$ positive cells and $\mathrm{C}=$ counter stained unlabelled cells. The tumour sections were scanned at lower magnification $(40 \times$ and $100 \times)$ for nonnecrotic areas and approximately 2000 total cells were counted for each section at higher magnification $(400 \times)$. The values of the three sections were averaged and the results of three independent CT-2A tumours were analysed.

\section{Proliferation index}

Proliferation index measured the fraction of cells with proliferating cell nuclear antigen (PCNA) staining as we previously described (Mukherjee et al, 1999a). After deparaffinisation, rehydration and washing, the tissue sections were soaked in $10 \mathrm{mM}$ citrate buffer $(\mathrm{pH}$ 6.0). The sections were heated in a microwave oven for 15 min (defrost cycle) and then cooled to room temperature to unmask the PCNA. Sections were then stained by the same procedures as described above except we used $10 \%$ horse serum as blocking agent and PCNA mouse monoclonal antibody (Dako) as the primary antibody. Light microscopy $(400 \times)$ was used to count both PCNA positive proliferating cells and total tumour cells in three non necrotic areas of each tissue section as previously shown (Mukherjee et al, 1999a).

\section{In vivo Matrigel model of angiogenesis}

Male BALB/c-SCID mice were divided into two groups of three mice each: a control AL group and a $30 \%$ DR group. Dietary restriction treatment was initiated 7 days prior to tumour cell injection. CT-2A tumour cells were grown in culture and harvested with $0.25 \%$ trypsin containing $1 \mathrm{mM}$ EDTA. The cells were washed twice, resuspended in serum free DMEM, and then thoroughly mixed with Matrigel (Collaborative Biomedical) $1: 2\left(\mathrm{v} \mathrm{v}^{-1}\right)$ at $4^{\circ} \mathrm{C}$ as we recently described (Manfredi et al, 1999). Mice were anaesthetised with Isovet (Schering Plough Animal Health, Omaha, NE, USA) and then injected with $1 \times 10^{6}$ cells in $300 \mu$ lof Matrigel subcutaneously in the dorsal midline using a prechilled tuberculin syringe (27 gauge needle). The mice were maintained for another 7 days under the dietary regime at which time they were euthanised and the Matrigel plug with the surrounding skin was removed as we previously described (Manfredi et al, 1999). Vascularity was photographed using a dissecting photomicroscope (Leica, WILD macroskop).

\section{RESULTS}

No adverse effects were seen in the mice maintained on the $30-$ $40 \%$ DR. Despite a reduction in total body weight, the DR-fed mice appeared healthy and were more active than the AL-fed mice as assessed by ambulatory and grooming behaviour. No signs of vitamin or mineral deficiency were observed in the DR-fed mice according to standard criteria for mice (Hoag and Dickie, 1968). These findings are consistent with the well-recognized health benefits of mild to moderate diet restriction in rodents (Weindruch and Walford, 1988; Keenan et al, 1999).

\section{Energy Intake}

Our experimental design involved pretreatment with DR for 7 days prior to intracerebral tumour implantation. This was done to separate the physiological stress of single cage housing and food restriction from surgical brain trauma. A slight reduction in energy intake was noticed in both the AL-fed and the DR-fed mice at the initiation of the experiment (Figure 1). This was attributed to the effects of moving the mice from group housing to single cage housing.
Energy intake increased significantly in the AL-fed group about 2 days after intracerebral tumour implantation. This resulted from a period of hyperphagia likely associated with cerebral hyperglycolysis following the traumatic injury of tumour implantation (Bergsneider et al, 1997). Energy intake was not increased in the DR-fed mice to compensate for hyperphagia. Consequently, energy intake was indirectly reduced in the DR-fed mice from $30 \%$ to about $40 \%$ of that in the control AL-fed group. Hyperphagia associated with orthotopic brain tumour growth is a novel finding and was not observed in C57BL/6J mice with the CT-2A tumour grown subcutaneously in flank (Ranes et al, 2001).

The total energy intake of the AL-fed group was about $18 \mathrm{Kcal}$ day $^{-1}$, but rose to about $24 \mathrm{Kcal} \mathrm{day}^{-1}$ during the hyperphagic period (Figure 1). The total energy intake of the DR-fed group was adjusted to $13 \mathrm{Kcal} \mathrm{day}^{-1}$ during the 22 day experiment. The DR-fed mice lost about 12\% of their body weight during the first week of treatment and their weights remained significantly lower than those of the AL group throughout the study. The mean $( \pm$ s.e.m.) body weights $(\mathrm{g})$ of the AL and DR mice after 17 days of treatment were $23.6 \pm 0.6$ and $20.3 \pm 0.4$, respectively $(P<0.01$, two tailed $t$-test). Total energy intake and body weights dropped after 17 days in the AL-fed group due to increased tumour burden.

\section{DR reduced intracerebral CT-2A tumour growth}

Dry weights of the intracerebral CT-2A tumours were approximately $79.5 \%$ lower in the DR-fed mice than in the AL-fed mice (Figure 2). It is important to mention that all implanted tumours grew in both the AL and DR groups. These findings indicate that DR did not prevent tumour take, but significantly reduced intracerebral growth of the malignant CT-2A brain tumour. We do not think the reduced food intake beyond day 19 in the control $\mathrm{AL}$ mice reduced the difference in tumor size between the $\mathrm{AL}$ and CR mice.

\section{Influence of DR on tumour vascularity, apoptosis, and cell proliferation}

We next examined tumour morphology and blood vessel densities using H\&E staining and Factor VIII immunostaining to determine if DR influenced tumour angiogenesis. Three independent tumours from the $\mathrm{AL}$ and $\mathrm{DR}$ groups were chosen at random for these studies. The number and size of blood vessels and tumour cell density were noticeably less in the DR-fed mice than in the ALfed mice (Figure 3A,B). Also, the tumour microvessel density of the DR-fed mice was about half of that in the AL-fed mice (Figure 3C,D, and Table 1).

To determine if DR influenced programmed cell death (apoptosis) in the CT-2A tumour, we compared the number of TUNEL positive cells (apoptotic index) in the AL-fed and DR-fed mice. The apoptotic index was almost three-fold greater in the DR mice than in the AL mice (Figure 3E,F and Table 1). No significant difference was found, however, between the DR and AL mice for the PCNA proliferation index (Table 1), suggesting that the DRinduced reduction of CT-2A growth was not associated with reduced tumour cell proliferation.

\section{DR reduced vascularity in the in vivo Matrigel model of angiogenesis}

The in vivo Matrigel angiogenesis model represents early events of angiogenesis and tumour progression and is dependent on activation and infiltration of host stromal cells which include monocytes, macrophages, and endothelial cell precursors (Manfredi et al, 1999). DR reduced vascularity when the CT-2A tumour cells were grown in the in vivo Matrigel model of angiogenesis (Figure 4). Although blood vessel quantitation is difficult in the plugs, it is clear from the figure that both the number and dilation of vessels 


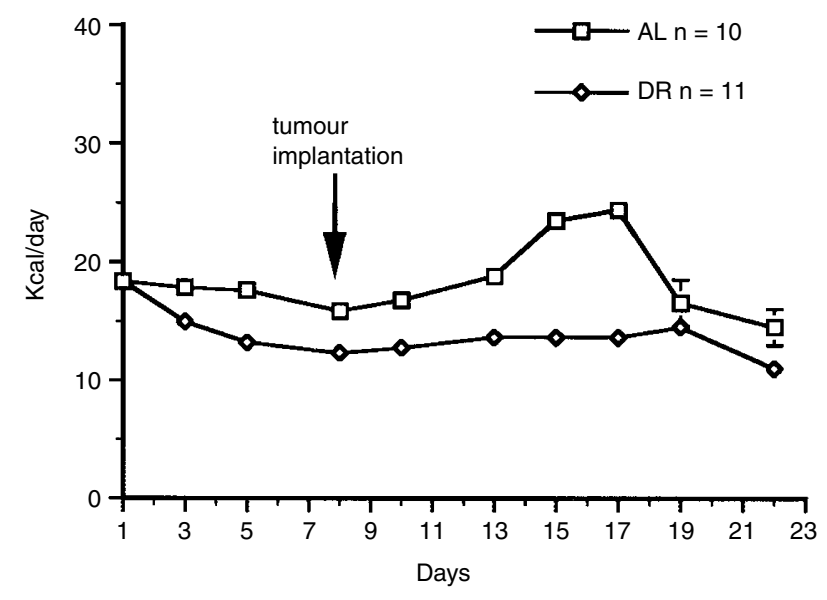

Figure I Energy intake in male C57BL6/] mice bearing the intracerebral CT-2A brain tumour. DR was initiated on day I and tumours were implanted on day 8 . Values are expressed as means \pm s.e.m. and $n=$ the number of tumour-bearing mice examined in each group.

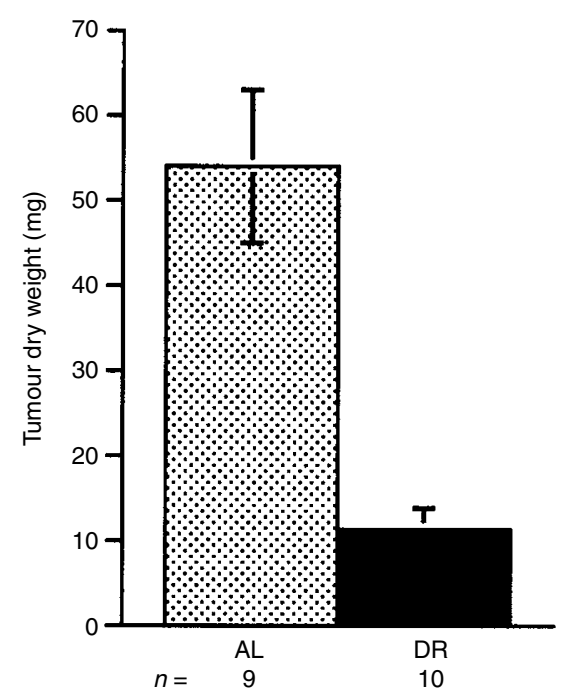

Figure 2 Influence of DR on the intracerebral growth of the CT-2A brain tumour. DR was initiated 7 days before tumour implantation and was continued for 14 days after implantation as shown in Figure I. Values are expressed as means \pm s.e.m. and $n=$ the number of tumour-bearing mice examined in each group. The dry weight of the treated tumours was significantly lower than that of the control tumours $(P<0.001$, two tailed $t$-test).

Table I Effects of dietary restriction on microvessel density, apoptosis, and proliferation index in the CT-2A brain tumour

\begin{tabular}{lclc}
\hline Treatment $^{\mathbf{a}}$ & $\begin{array}{c}\text { Microvessel density } \\
\text { vessels/high-power field }\end{array}$ & $\begin{array}{c}\text { Apoptotic } \\
\text { index } \boldsymbol{\%}^{\mathbf{c}}\end{array}$ & $\begin{array}{c}\text { Proliferation } \\
\text { index } \text { \% }^{\mathbf{d}}\end{array}$ \\
\hline $\mathrm{AL}$ & $27.3 \pm 3.9$ & $3.8 \pm 0.9$ & $71.5 \pm 5.8$ \\
$\mathrm{DR}$ & $13.0 \pm 2.0 *$ & $9.9 \pm 0.6 * *$ & $69.7 \pm 4.9$ \\
\hline
\end{tabular}

${ }^{a}$ Animals were fed either AL or under DR as described in Materials and Methods. Three independent tumours chosen at random were analysed in each group and all values are expressed as means \pm s.e.m. The asterisks indicate that the values from the DR group differed from $A L$ group at $P<0.05^{*}$, and $P<0.01 * *$ as determined by the two tailed $t$-test. The details for each measurement are described in Materials and Methods. 'Factor VIII-positive microvessels were averaged in three hotspot areas of each tumour section at $200 \times$. ' Apoptotic index, determined from the TUNEL assay. ${ }^{\mathrm{d}}$ Proliferation index, determined from the PCNA assay. was noticeably less in and around the plugs from the DR-fed mice than from the AL-fed mice. Similar qualitative differences were seen in the other independent sample. These findings indicate that DR reduces the angiogenic properties of the CT-2A tumour cells whether grown within or outside of the central nervous system.

\section{DISCUSSION}

We found that a moderate DR of $30-40 \%$ significantly reduced angiogenesis and growth of the CT-2A experimental mouse astrocytoma. Moreover, DR enhanced CT-2A cell apoptosis without effecting cell proliferation. Previous studies showed that moderate DR could reduce the growth of histologically diverse non-neural tumours (Rous, 1914; Tannenbaum, 1959; Kritchevsky, 1999a; Mukherjee et al, 1999a). Our studies are the first to document this phenomenon in a brain tumour model and suggest that brain tumours may be especially vulnerable to the growth-inhibitory effects of DR. It will be important to document the extent to which DR reduces angiogenesis and growth in other brain tumour models.

Despite a $12 \%$ reduction in body weight, the DR-fed mice were more active and healthy than the AL fed mice. Keenan and coworkers recently suggested that the AL feeding of sedentary rodents is a form of over feeding that can produce adverse health effects (Keenan et al, 1999). Our results support this contention since CT-2A tumour angiogenesis and growth was significantly greater in mice under AL feeding than under DR.

We found that angiogenic biomarkers may be useful for evaluating the influence of energy intake and nutrition on the growth and progression of experimental brain cancer. Moderate DR significantly reduced microvessel density, increased the apoptotic index, but had little effect on the PCNA labelling index in the CT-2A brain tumour. Other investigators have also reported that antiangiogenic growth factors and cytokines can reduce tumour microvessel density, increase apoptosis, but have little effect on cell proliferation (Holmgren et al, 1995; O'Reilly et al, 1996; Tanaka et al, 1997; Beecken et al, 2001). Our results therefore support previous findings that DR produces a pattern of biomarker changes similar to the changes seen following the implementation of antiangiogenic therapies (Mukherjee et al, 1999a; 1999b).

The mechanisms by which DR reduced CT-2A tumour angiogenesis and growth are not yet clear, but may involve effects on both the tumour cells and the tumour-associated host cells. It is documented that human and experimental gliomas are dependent on glycolysis for energy (Mies et al, 1990; Ikezaki et al, 1992; Oudard et al, 1997), and that DR-induced caloric restriction reduces glycolytic energy and down-regulates glycolytic gene expression (Lee et al, 2000; Cao et al, 2001; Greene et al, 2001). Additionally, the DR-induced down regulation of glycolysis should also reduce the level of pyruvic acid, a glycolytic end product with angiogenic activity (Lee et al, 2001).

Glucose is used exclusively for adult brain energy metabolism under normal physiological conditions, but the brain will metabolise ketone bodies for energy when blood glucose levels decrease as during fasting or DR (Clarke and Sokoloff, 1999; Greene et al, 2001). Since ketone bodies are metabolised directly to acetyl-CoA in the mitochondria, they bypass cytoplasmic glycolysis and provide energy directly through the Krebs cycle (Nehlig and Pereira de Vasconcelos, 1993; Clarke and Sokoloff, 1999). We recently showed that DR produces ketosis in epileptic mice and that the degree of ketosis is inversely proportional to blood glucose levels (Greene et al, 2001). Further studies will be needed to determine if reduced glycolytic energy and elevated ketosis underlie the antiangiogenic and growth inhibitory effects of DR.

In addition to possible effects on energy metabolism, DR may also reduce CT-2A angiogenesis and growth through effects on tumour associated host cells. The progression of human and experimental brain tumours is dependent to a large extent on 
$\mathrm{AL}$
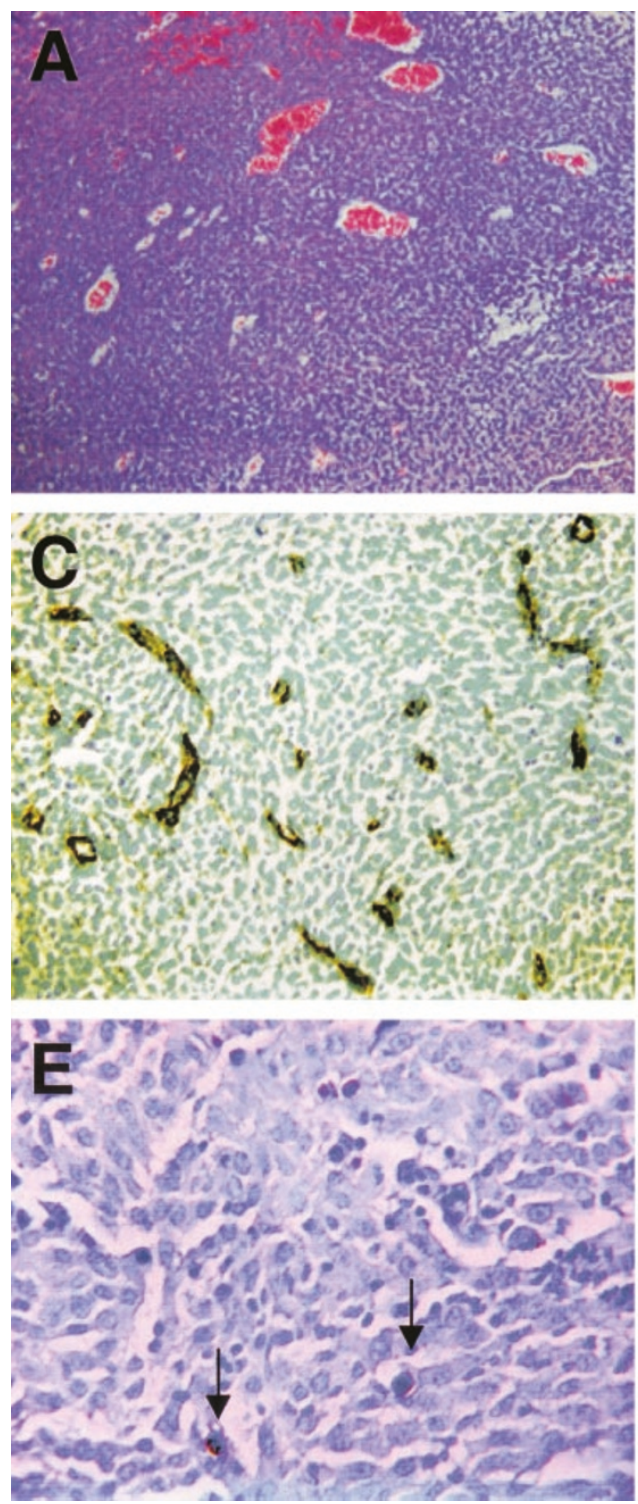

DR
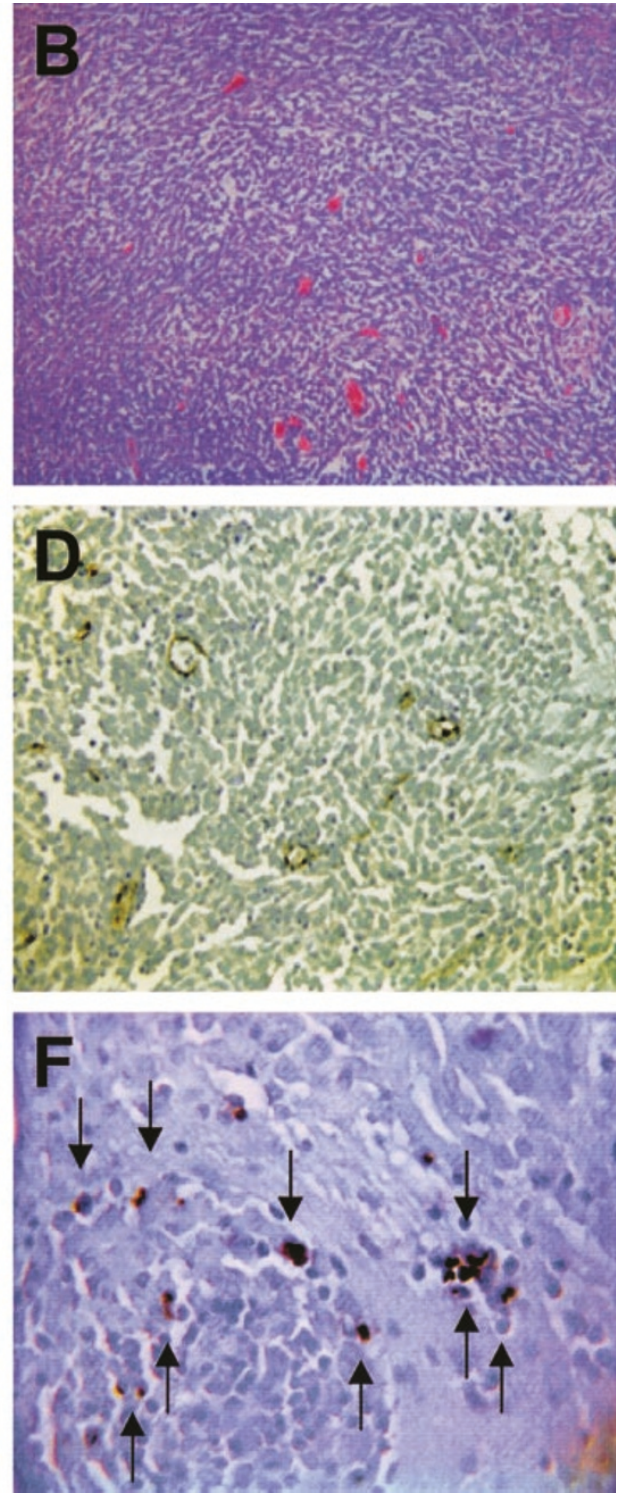

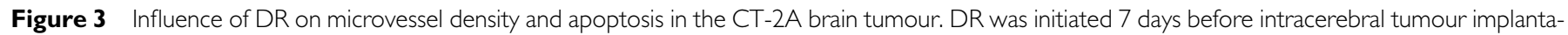

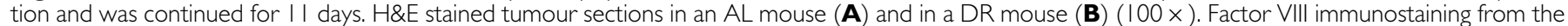

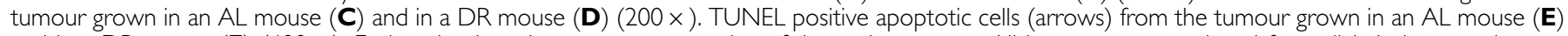
and in a DR mouse $(\mathbf{F})(400 \times)$. Each stained section was representative of the entire tumour. All images were produced from digital photography.

the proangiogenic and inflammatory properties of activated glia and macrophages (Seyfried, 2001). Indeed, the degree of tumour angiogenesis and malignancy is generally correlated with the number and activation state of tumour-associated macrophages and microglia (Wood and Morantz, 1979; Roggendorf et al, 1996; Nishie et al, 1999; Polverini, 1999; Badie and Schartner, 2000). Recent studies also indicate that moderate DR reduces brain inflammation associated with ageing and neurodegeneration (Duan et al, 2001; Lee et al, 2000). Furthermore, dietary energy restriction can elevate glucocorticoid hormone that could further reduce tumour inflammation and growth through down regulation of stress-activated protein kinase pathways (Birt et al, 1999). Hence, DR may reduce CT-2A progression through a global down-regulation of inflammatory and angiogenic properties of the tumour microenvironment.

We also found that DR caused a noticeable reduction in the number and the dilation of blood vessels in the in vivo Matrigel model of angiogenesis indicating that DR can reduce angiogenesis both within and outside of the central nervous system. It is possible that DR reduces the inflammatory properties of tumourassociated host cells and thereby shifts tumour-host cell interactions from a proangiogenic to an antiangiogenic state. Studies are planned to test these possibilities.

Our findings may have relevance to those in vivo studies where food intake and body weight are reduced in conjunction with anticancer therapies or with cancer cachexia. Reduction of energy intake as a covariable of anorexic anticancer therapies may confound interpretation of results (Ranes et al, 2001). It would be important therefore to control for the antitumour effects of dietary reduction in the preclinical evaluation of new cancer drugs. Weight loss associated with cancer cachexia differs from weight loss associated with anorexia (reduction in food intake) since cachexia can occur without anorexia and is produced from factors released by the tumour (Tisdale, 2001). Although appearing counterintui- 

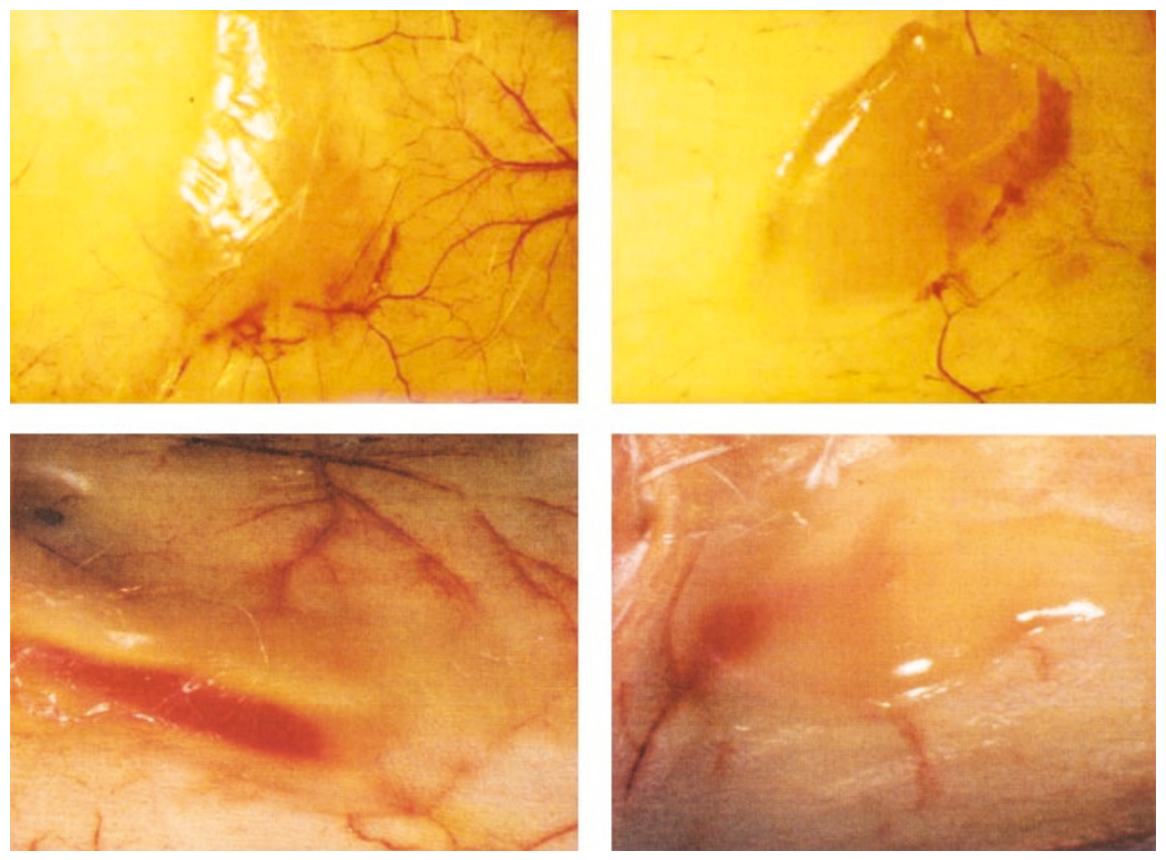

$\mathrm{AL}$

DR

Figure 4 Tumour cell-induced vascularity in the in vivo Matrigel plug assay. CT-2A tumour cells in Matrigel were injected s.c. in the flank of a BALB/C-SCID mouse as described in Materials and Methods. DR treatment was initiated 7 days prior to tumour cell injection. The Matrigel plugs with surrounding skin were removed on day 7 after implantation and photographed at $12.5 \times$.

tive, we suggest that DR may antagonise cachexia by reducing tumour size and therby reducing levels of procachexic factors.

Although DR is recognised as a preventative measure for carcinogenisis, it is clear from our findings on the the CT-2A brain tumour that DR is not a preventative intervention since all of the tumours implanted grew despite the 7 day DR pretreatment period. The DR-induced inhibition of CT-2A angiogenesis and growth suggests that DR retards tumour progression. Whether DR would also increase the survival time of CT-2A-tumour bearing mice is not clear. Survival studies are difficult with this rapidly growing brain tumour model since the tumour will grow through the implantation burr hole and then subcutaneously over the skull as we previously described for the EPEN model (Seyfried et al, 1987). This relieves intracranial pressure and artificially extends longevity. In humans with malignant brain tumours, it is the intracranial pressure that usually leads to morbidity.

In summary, we have demonstrated that DR alone can reduce angiogenesis and growth in an experimental mouse brain tumour. Moreover, the antitumour action of DR likely operates through multiple effects on the tumour cells and on the tumour associated host cells. We contend that our experimental protocol may have therapeutic potential for recurrent human gliomas since the time of surgical tumour resection in humans would be comparable to the time of tumour transplantation in mice. In other words, implementation of DR in the clinic could be most effective immediately following tumour removal and may delay tumour recurrence. Because DR is easy to administer and is devoid of adverse side effects, our preclinical studies suggest that DR or caloric restriction may have efficacy as a non-invasive therapy for recurrent malignant brain cancers.

\section{ACKNOWLEDGEMENTS}

This work was supported in part from NIH grant (HD39722), The Boston College Research Expense Fund, and a grant from the American Institute of Cancer Research. We would like to thank Dr Grant Balkema and the Dana-Farber/Harvard Cancer Center Pathology Core Facilities for technical assistance.

\section{REFERENCES}

Badie B, Schartner JM (2000) Flow cytometric characterization of tumorassociated macrophages in experimental gliomas. Neurosurgery 46: $957-$ 961

Beecken WD, Fernandez A, Joussen AM, Achilles EG, Flynn E, Lo KM, Gillies SD, Javaherian K, Folkman J, Shing Y (2001) Effect of antiangiogenic therapy on slowly growing, poorly vascularized tumors in mice. J Natl Cancer Inst 93: $382-387$

Bergsneider M, Hovda DA, Shalmon E, Kelly DF, Vespa PM, Martin NA, Phelps ME, McArthur DL, Caron MJ, Kraus JF, Becker DP (1997) Cerebral hyperglycolysis following severe traumatic brain injury in humans: a positron emission tomography study. J Neurosurg 86: $241-251$

Birt DF, Yaktine A, Duysen E (1999) Glucocorticoid mediation of dietary energy restriction inhibition of mouse skin carcinogenesis. J Nutr 129: $571 S-574 S$

Black PM (1991) Brain tumors. Part 1. N Engl J Med 324: 1471-1476

Blowers L, Preston-Martin S, Mack WJ (1997) Dietary and other lifestyle factors of women with brain gliomas in Los Angeles County (California, USA). Cancer Causes Control 8: 5-12

Cao SX, Dhahbi JM, Mote PL, Spindler SR (2001) Genomic profiling of short- and long-term caloric restriction effects in the liver of aging mice. Proc Natl Acad Sci USA 98: 10630-10635

Clarke DD, Sokoloff L (1999) Circulation and energy metabolism in the brain. In Basic Neurochemistry, Siegel GJ, Agranoff BW, Albers RW, Fisher SK, Uhler MD (eds) pp 637-669. New York: Lippincott-Raven

Duan W, Lee J, Guo Z, Mattson MP (2001) Dietary restriction stimulates BDNF production in the brain and thereby protects neurons against excitotoxic injury. J Mol Neurosci 16: $1-12$ 
Flavin HJ, Wieraszko A, Seyfried TN (1991) Enhanced aspartate release from hippocampal slices of epileptic (El) mice. J Neurochem 56: 1007-1011

Greene AE, Todorova MT, McGowan R, Seyfried TN (2001) Caloric restriction inhibits seizure susceptibility in epileptic EL mice by reducing blood glucose. Epilepsia 42: 1371-1378

Hoag WG, Dickie MM (1968) Nutrition. In Biology of the Laboratory Mouse, Green EL (ed). New York: Dover

Holmgren L, O’Reilly MS, Folkman J (1995) Dormancy of micrometastases: balanced proliferation and apoptosis in the presence of angiogenesis suppression. [see comments] Nat Med 1: 149-153

Hu J, La Vecchia C, Negri E, Chatenoud L, Bosetti C, Jia X, Liu R, Huang G, Bi D, Wang C (1999) Diet and brain cancer in adults: a case-control study in northeast China. Int J Cancer 81: 20-23

Ikezaki K, Black KL, Conklin SG, Becker DP (1992) Histochemical evaluation of energy metabolism in rat glioma. Neurol Res 14: 289-293

Kaiser J (1999) No meeting of minds on childhood cancer. Science 286: $1832-1834$

Kaplan S, Novikov I, Modan B (1997) Nutritional factors in the etiology of brain tumors: potential role of nitrosamines, fat, and cholesterol. Am J Epidemiol 146: $832-831$

Keenan KP, Ballam GC, Soper KA, Laroque P, Coleman JB, Dixit R (1999) Diet, caloric restriction, and the rodent bioassay. Toxicol Sci 52: 24-34

Kritchevsky D (1999a) Caloric restriction and experimental carcinogenesis. Toxicol Sci 52: $13-16$

Kritchevsky D (1999b) Fundamentals of nutrition: applications to cancer research. In Nutritional Oncology, Heber D, Blackburn GL, Go VLW (eds) pp 5-10. Boston: Academic Press

Lee CK, Weindruch R, Prolla TA (2000) Gene-expression profile of the ageing brain in mice. Nat Genet, 25: 294-297

Lee MS, Moon EJ, Lee SW, Kim MS, Kim KW, Kim YJ (2001) Angiogenic activity of pyruvic acid in in vivo and in vitro angiogenesis models. Cancer Res 61: 3290-3293

Lowry JK, Snyder JJ, Lowry PW (1998) Brain tumors in the elderly: recent trends in a Minnesota cohort study. Arch Neurol 55: 922-928

Manfredi MG, Lim S, Claffey KP, Seyfried TN (1999) Gangliosides influence angiogenesis in an experimental mouse brain tumor. Cancer Res 59: 5392 5397

McKinley BP, Michalek AM, Fenstermaker RA, Plunkett RJ (2000) The impact of age and sex on the incidence of glial tumors in New York state from 1976 to 1995. J Neurosurg 93: $932-939$

Mies G, Paschen W, Ebhardt G, Hossmann KA (1990) Relationship between of blood flow, glucose metabolism, protein synthesis, glucose and ATP content in experimentally-induced glioma (RG1 2.2) of rat brain. $J$ Neurooncol 9: $17-28$

Mukherjee P, El-Abbadi MM, Kasperzyk JL, Seyfried TN (2001) Caloric restriction reduces growth and angiogenesis in a mouse brain tumor. Proc Amer Assoc Cancer Res 42: 651-652

Mukherjee P, Sotnikov AV, Mangian HJ, Zhou JR, Visek WJ, Clinton SK (1999a) Energy intake and prostate tumor growth, angiogenesis, and vascular endothelial growth factor expression. J Natl Cancer Inst 91: $512-523$

Mukherjee P, Zhau J-R, Sotnikov AV, Clinton SK (1999b) Dietary and nutritional modulation of tumor angiogenesis. In Antiangiogenic Agents in Cancer Therapy, Teicher BA (ed) pp 237-261. Totowa, NJ: Humana Press

Nebeling LC, Miraldi F, Shurin SB, Lerner E (1995) Effects of a ketogenic diet on tumor metabolism and nutritional status in pediatric oncology patients: two case reports. J Am Coll Nutr 14: 202-208
Nehlig A, Pereira de Vasconcelos A (1993) Glucose and ketone body utilization by the brain of neonatal rats. Prog Neurobiol 40: 163-221

Nishie A, Ono M, Shono T, Fukushi J, Otsubo M, Onoue H, Ito Y, Inamura T, Ikezaki K, Fukui M, Iwaki T, Kuwano M (1999) Macrophage infiltration and heme oxygenase-1 expression correlate with angiogenesis in human gliomas. Clin Cancer Res 5: 1107-1113

O'Reilly MS, Holmgren L, Chen C, Folkman J (1996) Angiostatin induces and sustains dormancy of human primary tumors in mice. Nat Med 2: $689-692$

Oudard S, Boitier E, Miccoli L, Rousset S, Dutrillaux B, Poupon MF (1997) Gliomas are driven by glycolysis: putative roles of hexokinase, oxidative phosphorylation and mitochondrial ultrastructure. Anticancer Res 17: $1903-1911$

Pili R, Guo Y, Chang J, Nakanishi H, Martin GR, Passaniti A (1994) Altered angiogenesis underlying age-dependent changes in tumor growth. J Natl Cancer Inst 86: $1303-1314$

Polverini PJ (1999) Contribution of the extracellular matrix and macrophages in angiogenesis. In Antiangiogenic Agents in Cancer Therapy, Teicher BA (ed) pp 65-75. Totowa, New Jersey: Humana Press

Ranes MK, El-Abbadi M, Manfredi MG, Mukherjee P, Platt FM, Seyfried TN (2001) N -butyldeoxynojirimycin reduces growth and ganglioside content of experimental mouse brain tumours. Br J Cancer 84: 1107-1114

Roggendorf W, Strupp S, Paulus W (1996) Distribution and characterization of microglia/macrophages in human brain tumors. Acta Neuropathol 92: $288-293$

Rous P (1914) The influence of diet on transplanted and spontaneous mouse tumors. J Exp Med 20: 433-451

Seyfried TN (2001) Perspectives on brain tumor formation involving macrophages, glia, and neural stem cells. Perspect Biol Med 44: 263-282

Seyfried TN, El-Abbadi M, Roy ML (1992) Ganglioside distribution in murine neural tumors. Mol Chem Neuropathol 17: 147-167

Seyfried TN, Yu RK, Saito M, Albert M (1987) Ganglioside composition of an experimental mouse brain tumor. Cancer Res 47: 3538-3542

Shapiro WR (1999) Current therapy for brain tumors: back to the future. Arch Neurol 56: 429-432

Tanaka T, Manome Y, Wen P, Kufe DW, Fine HA (1997) Viral vectormediated transduction of a modified platelet factor $4 \mathrm{cDNA}$ inhibits angiogenesis and tumor growth. Nat Med 3: 437-442

Tannenbaum A (1959) Nutrition and cancer. In Physiopathology of Cancer, Homburge F (ed) pp 517-562. NY: Paul B Hober

Tisdale MJ (2001) Cancer anorexia and cachexia. Nutrition 17: 438-442

Weidner N, Semple JP, Welch WR, Folkman J (1991) Tumor angiogenesis and metastasis - correlation in invasive breast carcinoma. $N$ Engl J Med 324: $1-8$

Weindruch R, Walford RL (1988) The retardation of aging and disease by dietary restriction. Springfield, IL: Thomas

Wood GW, Morantz RA (1979) Immunohistologic evaluation of the lymphoreticular infiltrate of human central nervous system tumors. J Natl Cancer Inst 62: 485-491

Workman P, Twentyman P, Balkwill F, Balmain A, Chaplin D, Double J, Embleton J, Newell D, Raymond R, Stables J, Stephens T, Wallace J (1998) United Kingdom Co-ordinating Committee on Cancer Research (UKCCCR) Guidelines for the Welfare of Animals in Experimental Neoplasia (Second Edition). Br J Cancer 77: 1-10

Zimmerman HM, Arnold H (1941) Experimental brain tumors: I. tumors produced with methylcholanthrene. Cancer Res 1: 919-938 